Cinémas

Revue d'études cinématographiques

Journal of Film Studies

\title{
Présentation
}

\section{Martin Lefebvre}

Volume 1, numéro 1-2, automne 1990

Américanité et cinéma

URI : https://id.erudit.org/iderudit/1000986ar

DOI : https://doi.org/10.7202/1000986ar

Aller au sommaire du numéro

Éditeur(s)

Cinémas

ISSN

1181-6945 (imprimé)

1705-6500 (numérique)

Découvrir la revue

Citer ce document

Lefebvre, M. (1990). Présentation. Cinémas, 1(1-2), 4-6.

https://doi.org/10.7202/1000986ar d'utilisation que vous pouvez consulter en ligne.

https://apropos.erudit.org/fr/usagers/politique-dutilisation/ 


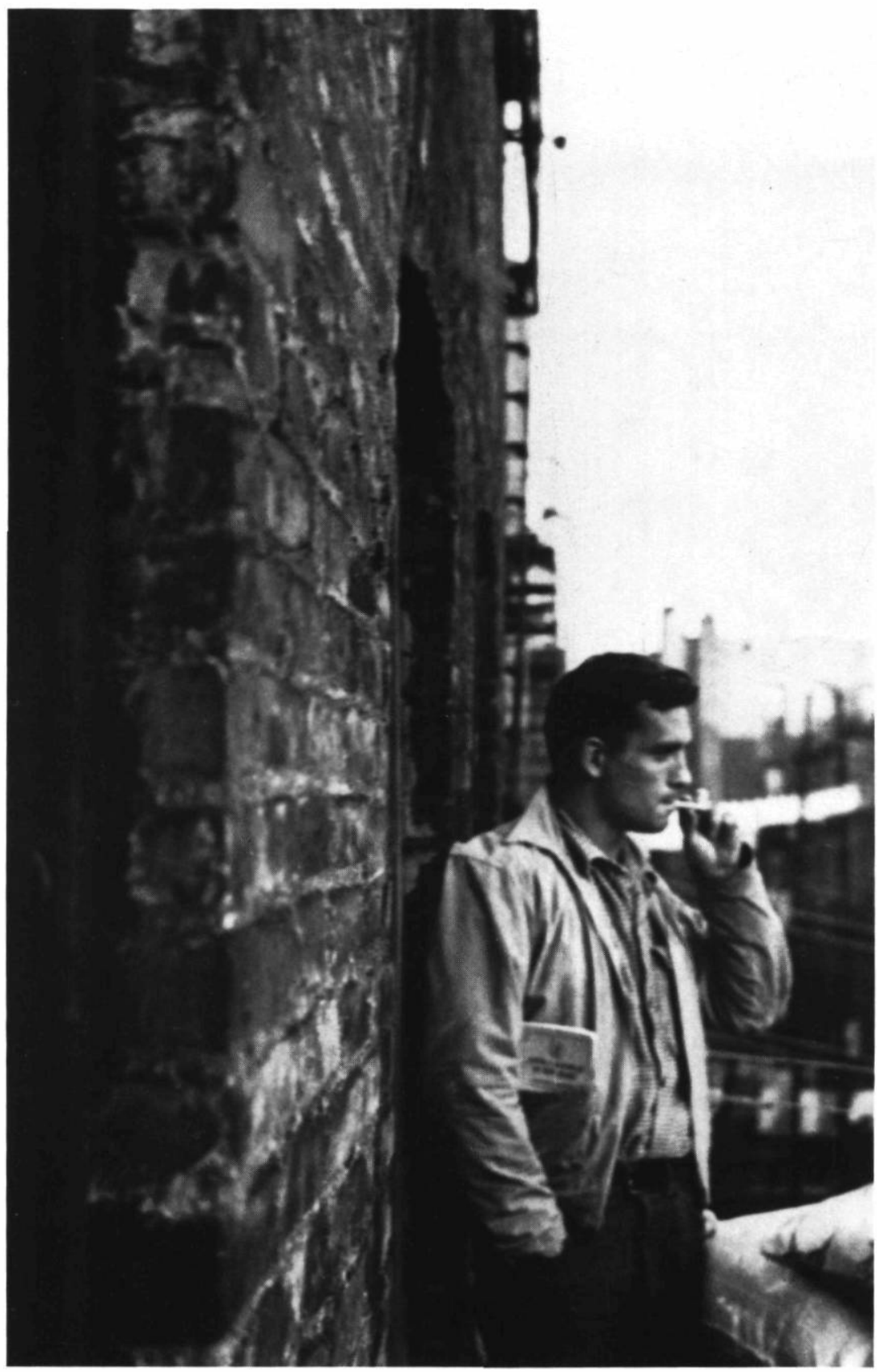

Le Grand Jack d'Herménégilde Chiasson (1988) Jack Kerouac, New York, 1953 (photo Allen Gisberg) Coll. ONF 


\section{Présentation}

\section{Martin Lefebvre}

L'importance de l'américanité dans la culture contemporaine ne fait aucun doute. Pourtant, plusieurs interrogations subsistent quant à sa nature: s'agit-il d'une forme symbolique, d'un mythe moderne ou d'une idéologie? Telles étaient, à l'origine, les questions qui ont orienté la conception de ce numéro de Cinémas. Aujourd'hui, au moment où les ordres politique, économique, géographique et environnemental de l'après-guerre sont bouleversés de par le monde, à l'heure de l'Allemagne réunifiée, d'une Europe de l'Est plus souveraine, du libre-échange canado-«étatsunien», de la Nouvelle Europe économique et de la menace pesant sur la couche d'ozone, le besoin de trouver des réponses et des questions se fait de plus en plus aigu. C'est par le biais du cinéma que nous avons cherché à rendre compte de l'américanité. Le cinéma est après tout un des lieux privilégiés pour essayer de cerner les différentes figures de l'américanité. Notion charnière dans le paysage nouveau de la mondialisation et de l'homogénéisation des cultures, l'américanité, tout comme le cinéma, appartient au $\mathrm{XX}^{\mathrm{e}}$ siècle. Ce ne serait là qu'un banal rapprochement si ce n'était qu'ils partagent tous les deux beaucoup plus: tout comme l'américanité a profité du cinéma pour l'établissement de son hégémonie, le cinéma a profité de l'américanité pour établir la sienne. Jeu de renforcements réciproques et dont on connaît l'influence, depuis la fin de la Deuxième Guerre mondiale, sur les habitudes sociétales ainsi que sur les manières de faire du cinéma. Le fameux american way of life a restructuré les besoins de la société post-industrielle — on mange maintenant des Big Macs à Moscou — et maintes industries cinématographiques dévastées par la guerre - comme en témoigne la création de studios «à l'américaine» en Italie ou au Japon après 1945. Depuis lors, l'américanité dépasse le territoire de l'Amérique et du cinéma américain et déborde dans le territoire imaginaire des cinématographies nationales. 
C'est d'ailleurs largement autour des questions du territoire et de l'altérité que s'organisent les contributions théoriques et méthodologiques du présent numéro. Le dossier est constitué de quatre doublets.

Le premier mouvement est centré sur la spatialisation de la culture et notamment sur les différences verticales et horizontales qui animent les rapports entre Ancien et Nouveau Monde (développement, à partir d'une perspective québécoise, de deux modèles antagoniques faisant foi des tensions entre culture populaire et culture savante), et qui informent la représentation cinématographique de l'espace (mise en scène de la ville américaine dans le cinéma américain et européen).

Le deuxième mouvement s'intéresse plus spécifiquement au territoire américain et aux dépossédés de ce territoire: étude sur Hollywood (construite aux limites de la frontière occidentale des États-Unis sur les cadavres des habitants réels du territoire américain: les Indiens), analyse du discours western et de son influence sur la figuration des personnages indiens dans le cinéma américain.

Le troisième volet est consacré aux mutations et aux croisements culturels impliqués dans le passage vers le territoire de l'Autre. Passages économiques et surtout culturels dans le cas des coproductions québécoises (où s'animent de plus en plus les questions d'identification et d'altérité) et passage difficile d'un cinéaste français - Renoir - aux États-Unis, aux prises avec la vision schématisée, stéréotypée et manichéenne du cinéma américain.

Le quatrième volet examine spécifiquement les rapports entre les territoires québécois et américain à partir des films de la série «L'Américanité», produite par l'Office national du film du Canada. On montre comment cette série s'est construite autour d'un vide, autour de l'absence de définition de la notion d'américanité, ce qui explique que la série soit aux prises avec un conflit en ce qui concerne son traitement de l'altérité.

En résumé, il appert que la notion d'américanité, aussi diffuse et plurielle qu'elle soit encore dans ses thèmes et contenus, prend forme autour de la question du territoire, que ce soit celui qu'on analyse ou celui à partir duquel on parle. C'est pourquoi, d'ailleurs, la frontière entre les diverses problématiques présentées dans ce numéro n'est aucunement étanche. Nous encourageons le lecteur à y trouver d'autres passages et d'autres parcours.

University of Alberta 